\title{
Increasing Statistical Literacy by Exploiting Lexical Ambiguity of Technical Terms
}

Jennifer J. Kaplan

University of Georgia, jkaplan@uga.edu

Neal Rogness

Grand Valley State University, rognessn@gvsu.edu

Follow this and additional works at: https://digitalcommons.usf.edu/numeracy

Part of the Science and Mathematics Education Commons

\section{Recommended Citation}

Kaplan, Jennifer J., and Neal Rogness. "Increasing Statistical Literacy by Exploiting Lexical Ambiguity of Technical Terms." Numeracy 11, Iss. 1 (2018): Article 3. DOI: https://doi.org/10.5038/1936-4660.11.1.3 


\title{
Increasing Statistical Literacy by Exploiting Lexical Ambiguity of Technical Terms
}

\begin{abstract}
Instructional inattention to language poses a barrier for students in entry-level science courses, in part because students may perceive a subject as difficult solely based on the lack of understanding of the vocabulary. In addition, the technical use of terms that have different everyday meanings may cause students to misinterpret statements made by instructors, leading to an incomplete or incorrect understanding of the domain. Terms that have different technical and everyday meanings are said to have lexical ambiguity and statistics, as a discipline, has many lexically ambiguous terms. This paper presents a cyclic process for designing activities to address lexical ambiguity in statistics. In addition, it describes three short activities aimed to have high impact on student learning associated with two different lexically ambiguous words or word pairs in statistics. Preliminary student-level data are used to assess the efficacy of the activities, and future directions for development of activities and research about lexical ambiguity in statistics in particular and STEM in general are discussed.
\end{abstract}

\section{Keywords}

Lexical Ambiguity, Statistics Education, Undergraduate Student Learning

Creative Commons License

(c) (1) (9)

This work is licensed under a Creative Commons Attribution-Noncommercial 4.0 License

\section{Cover Page Footnote}

Jennifer Kaplan is an Associate Professor in the Department of Statistics at the University of Georgia. Her research area is undergraduate statistics education. Currently, the main focus of her research involves improving student learning through professional development and pedagogical reform. The work reported in this paper is part of a decade long collaboration funded most recently by the National Science Foundation through the HILT-LAS project. In addition, Dr. Kaplan is the Editor of Regular Papers for the Statistics Education Research Journal (SERJ).

Neal Rogness is a Professor in the Department of Statistics at Grand Valley State University. His research area is in undergraduate statistics education with an emphasis on the intersection of language and student learning of statistics. Recently, Dr. Rogness has also been exploring the use of Team Based Learning as a pedagogical method in the introductory statistics course and hopes to pursue collaborative research in this area as well. 


\section{Introduction}

Education researchers in the STEM fields have long noted the barrier to entry that language poses for students studying science (e.g., Lemke 1990; Roth 2005; Brown and Ryoo 2008; Rector et al. 2013). Brown $(2006,188)$ reports that high school students find science "difficult sometimes because of the big words, people don't understand what they mean' and concludes that the use of technical language unfamiliar to students causes students to de-identify with and distance themselves from science, restricting access to science learning for such students. From a socio-constructivist perspective, language is also a tool for participation in a community of practice (Espinet et al. 2012). Thus, inattention to language in the classroom represents a barrier to student entry into a subject, as students perceive a subject as difficult solely based on the lack of understanding of the vocabulary (Brown 2006; Brown and Ryoo 2008).

Language plays a crucial role in the classroom. It is a major means of communication of new ideas (Espinet et al. 2012). It helps students build understanding and process ideas (Espinet et al. 2012), and it provides a method by which student learning is assessed (Brown and Ryoo 2008; Thompson and Rubenstein 2000). Pinker (1994, 1) makes a powerful statement about language: "Simply by making noises with our mouths, we can reliably cause precise new combinations of ideas to arise in each other's minds." Can an instructor, however, be sure the combination of new ideas arising in students' minds is precisely what he or she wishes? What happens in the learning cycle if the words we use as instructors do not have the same meaning for students as they do for us? Roth $(2005,166)$ concludes that unless students and teachers are using words in the same way, "there is a vast amount of room for misunderstanding that may never be detected."

The potential negative impact of spoken discourse on student affect and learning of quantitative literacy is noted by Tunstall (2016). The term quantitative literacy (QL) and its related terms, quantitative reasoning (QR) and numeracy, may themselves have different meanings for researchers in different education research fields (Vacher 2014; Karaali et al. 2016). Similarly, the term statistical literacy has a number of related definitions, from understanding the basic language of statistics (e.g., knowing what statistical terms and symbols mean and being able to read statistical graphs [GAISE 2006]) to the ability to understand and critically evaluate statistical results and, when relevant, express opinions about statistical information, data-related arguments, or stochastic phenomena (Gal 2003). We define statistical literacy loosely as the set of knowledge and skills necessary for good consumers, rather than producers, of statistics. Taking the definition of QL and its related terms to describe the ability "to work 
successfully with numbers as they manifest in day-to-day living" (Tunstall 2016, 2) places statistical literacy in a foundational position for developing this QL.

This paper describes a process for detecting and addressing potential definitional and content misunderstandings in statistics that arise as a result of instructor use of lexically ambiguous words in the statistics classroom. While the focus of the paper is on vocabulary used in introductory statistics courses, the theory and findings are intended to be generalizable to the other disciplines that comprise the QL and QR family of competencies. As such, this paper may provide QL instructors practical suggestions for addressing the issues in classroom discourse raised by Tunstall (2016).

\section{Background}

Language acquisition is not a simple or straightforward process of learning definitive meanings of a collection of words (Leung 2005). Some words may have core meanings, where the word brings to mind a mental image. Even words that have core meanings, such as cat, may have associated characteristics that are not part of the core meaning. For example, black cat has connotations that are not necessarily included in the core meaning of cat. Words that do not have a clear core meaning, such as those that describe concepts, are even more difficult to incorporate into one's vocabulary (Leung 2005). One might consider helping students learn new words by listing the necessary and sufficient conditions that must be met by an object or concept to be named by a given word. Leung (2005) illustrates the impracticality of this idea in mathematics by providing four different published definitions of the word square. Each of the definitions lists a different set of necessary and sufficient conditions for an object to be classified as a square. Therefore, even after establishing that comprehending the meaning of a word means knowing its core meaning (when such an aspect exists) as well as its non-core meanings and the relationships between the various possible representations of meaning, there is still the issue of how such meanings are acquired. Leung's final argument for her claim that learning a word is not straightforward is to cite Schmitt's observation that learning the meaning of a word is an incremental process. The first time a person hears a word, the person will remember only one particular meaning sense of the word: the one in which it was used on that occasion. It is only after repeated exposures to the word that "basic formal and semantic features....are built up and consolidated" (Leung 2005, 131). So learning the nuances of word meanings is a long process that happens via repeated exposure.

In addition to the general issue of language acquisition, as students begin to take specialized subjects in middle or high school and become exposed to each subject's specialized vocabulary, they do not yet speak the language of the 
domain (Lemke 1990). The use of specialized language that is unfamiliar to the student portrays a subject as more difficult than it is, a subject that can only be mastered by geniuses (Lemke 1990). Furthermore, words "used to describe scientific concepts in terms of everyday phenomena often pose a problem for students" (Neibert et al. 2012, 866), perhaps because people connect what they hear to what they have heard and experienced in the past (Lemke 1990; Neibert et al. 2012). Therefore, using common everyday words as an alternative to technical terms might increase misunderstandings and barriers for students (Neibert et al. 2012). Incorporation of the use of everyday words, experiences, and analogies in mathematics and science education, must, therefore, be designed carefully to make strong connections between student experiences and the target learning objectives (Roth 2005; Brown and Spang 2008).

Similar words or phrases that have different meanings, whether the meanings are related or not, are said to have lexical ambiguity (Barwell 2005; Vacher 2014). In elementary school language arts, students learn about homonyms and homophones. Homophones are words that are spelled the same but have different meanings, such as leaves: those that grow on a tree and in the mathematical statement, seven minus four leaves three (Kaplan et al. 2009). Homophones are words that sound the same but have different meanings such as the value pi and the pie we eat (Kaplan et al. 2009). Two other potential lexical ambiguities that have been shown to exist in mathematical terms are polysemy and shifts of application (Durkin and Shire 1991a). Polysemous words are those that have two or more different but related meanings (Vacher 2014), such as product, an item that can be made or the result of a multiplication. Shifts of application occur when one word can mean different things in different contexts. For example, number can be nominal, cardinal, ordinal, or visual (Kaplan et al. 2009). Whenever a domain-specific word is similar to a commonly used English word but has a different meaning in a technical domain, it is said to have lexical ambiguity (Barwell 2005).

Lexical ambiguity and the acquisition of a linguistic register associated with a field has been shown to create problems for learners in science (Lemke 1990, Tomlinson, Dyson, and Garratt 2001; Garvin-Doxas and Klymkowsky 2008), mathematics (Shultz and Pilon 1973; Durkin and Shire 1991b), and statistics (Makar and Confrey 2005; Lesser et al. 2009, 2013; Kaplan et al. 2009, 2014). For example, undergraduate students in chemistry tend to think that errors in science refer to personal mistakes, rather than uncertainties associated with physical measurements, such as precision of the measuring device, that lead to variability in results (Tomlinson, Dyson, and Garratt 2001). In addition, undergraduate students in statistics tend to define random events as those that are haphazard, unlikely, or unusual (Kaplan et al. 2014), and undergraduate biology students define random processes as those that are inefficient, in contrast to 
biological processes, which they define as being efficient (Garvin-Doxas and Klymkowsky 2008).

The authors have collected student-written sentences and definitions for a number of potentially lexically ambiguous terms with technical meanings in statistics including: association, average, correlation, bias, confidence, error, independent, normal, parameter, random, skew, spread, and significant. Using the word average as an example, when collecting student definitions of average in their everyday usage prior to statistics instruction, about $40 \%$ of the students defined average as typical or normal (Kaplan et al. 2009). If students equate the word average with the word normal, we wondered whether this would mean students would think that the normal distribution was the typical or average distribution. We became even more concerned when, at the end of a one-semester introduction to statistics course, about $16 \%$ of students still gave a colloquial definition of average, such as standard, typical, normal or most common even when asked for a statistical definition of the word (Kaplan et al. 2010). In fact, as yet unpublished data indicate, when asked what it means for a variable to follow a normal distribution, a number of students at the end of a one-semester introduction to statistics course give responses such as:

It means the distribution is what we expected.

The distribution does not have any unusual values.

The distribution is similar to other distributions.

We hypothesize that these students either do not understand that a normal distribution is a family of unimodal and symmetric distributions that follow the Empirical Rule or think that the normal distribution is the most commonly occurring distribution and that these misunderstandings are the direct result of naming the distribution with a lexically ambiguous word, normal being a synonym of typical for our students.

One of the first steps in addressing lexical ambiguity in the classroom is for instructors to recognize words that have lexical ambiguity and try to preempt difficulties by careful use of language in their teaching (Rangecroft 2002; Albert 2003; Brown and Spang 2008; Lesser and Winsor 2009). In addition, instructors should be aware of students' everyday use of lexically ambiguous words and should address explicitly in the classroom the differences in meaning (Rangecroft 2002; Brown and Spang 2008; Lavy and Mashiach-Eizenberg 2009), through the use of multiples modes and representations (Brown and Spang 2008; Lesser et al. 2009, 2013), and by exploiting the differences between the uses (Adams et al. 2005). Instructors should help students to build their voices in the technical domain (Lemke 1990; Durkin and Shire 1991a; Adams et al. 2005; Brown and Spang 2008) through vocabulary activities and writing assignments (Durkin and Shire 1991a; Adams et al. 2005; Lesser et al. 2009, 2013). A study of students in 
an urban setting concluded that an emphasis on the importance of vocabulary prior to the introduction of terms associated with scientific classifications allowed the students to develop an understanding of the importance of learning the scientific language (Brown and Spang 2008).

\section{Intervention Process}

The cyclic process for designing activities to address lexical ambiguity in statistics developed by the authors is summarized as follows (Fig. 1):

1. Identify the lexically ambiguous target term.

2. Collect student-level data to understand student use of the term both prior to and after typical instruction without attention to potential lexical ambiguities.

3. Use the student-level data to

a) assess the severity of the lexical ambiguity associated with the target term, and

b) create a classroom activity that will help students develop correct technical use of the target term within the discipline of statistics by exploiting the ambiguity associated with the word.

4. Collect student-level data from students who experienced the activity to measure the success of the activity with respect to student understanding of the target term.

5. Revise the activity as necessary until the student-level data show the desired level of student understanding of the target term.

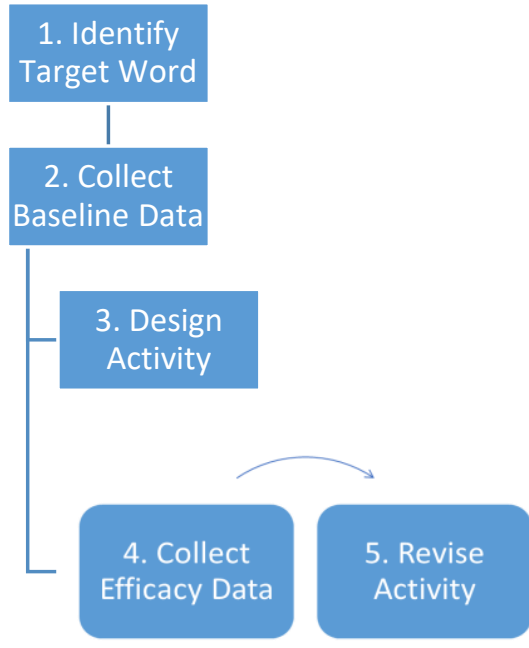

Figure 1. Development cycle for activities to address lexically ambiguous words. 
The student-level data in Step 2 of the cycle can by collected from students in any typical or set of typical institutions and undergraduate introductory statistics courses. The purpose of these data is to find out how students use the words in everyday settings and whether they can define the words statistically after typical instruction. The only reason to collect data from diverse locations would be if there were a concern about linguistic differences by region. The efficacy data collected in Step 4 should be from students at the same institution and course. This can be done either by collecting data longitudinally from students of the same instructors over time or by collecting data from students in comparable classes, those that did and did not experience the activity created in Step 3. It is desirable to develop activities in Step 3 that require little class time, making their usage attractive, while having a high impact on student learning. We call this class of activities "HILT" for High Impact (on student learning) but Little Time (to enact).

The first term to which the authors applied the described process was the word random. The process and results can be read in detail in Kaplan et al. (2014). In summary, the baseline data collected from students at the beginning of a statistics course indicate that nearly half of all students define random as an event that is haphazard, spontaneous, strange, or has no definite aim or purpose. Prior to instruction, most of the remaining students define random as a method of selection without order, reason, or definite plan or without prior knowledge, criteria, or agenda (Kaplan et al. 2008). In other words, students' colloquial definitions for random prior to instruction in statistics are something that is seemingly haphazard, with no pattern or design, or a strange occurrence. After typical instruction without attention to the potential lexical ambiguities associated with the word random, only $8 \%$ of students included the idea of probability in their definition of random. Many students still define random as something without order or pattern (39\%), although a certain number do connect random sampling with the production of a representative or unbiased sample (23\%) (Kaplan et al. 2009, 2014).

The activity created for the word random is call the "Zebra vs. Hat Activity." In the "Zebra vs. Hat Activity," students are shown a picture of people in rainbow-striped zebra costumes on a street corner in Shanghai to represent the colloquial meaning of random: a haphazard or unexpected occurrence (Fig. 2a). This meaning is contrasted with the technical meaning of random, which is demonstrated using a picture of a hat (Fig. 2b). Because drawing items from a hat represents a statistically random process, this picture captures the definition of random given by Moore (2007, 248): "We call a phenomenon random if individual outcomes are uncertain but there is nonetheless a regular distribution of outcomes in a large number of repetitions." The use of the two pictures in tandem provides instructors with an opportunity to exploit the lexical ambiguity of 
random by contrasting the two meanings, colloquial and technical, using images to which the instructor can easily refer over the course of the semester. For example, an instructor might say, "remember, when I say random, I mean the hat not the zebras."

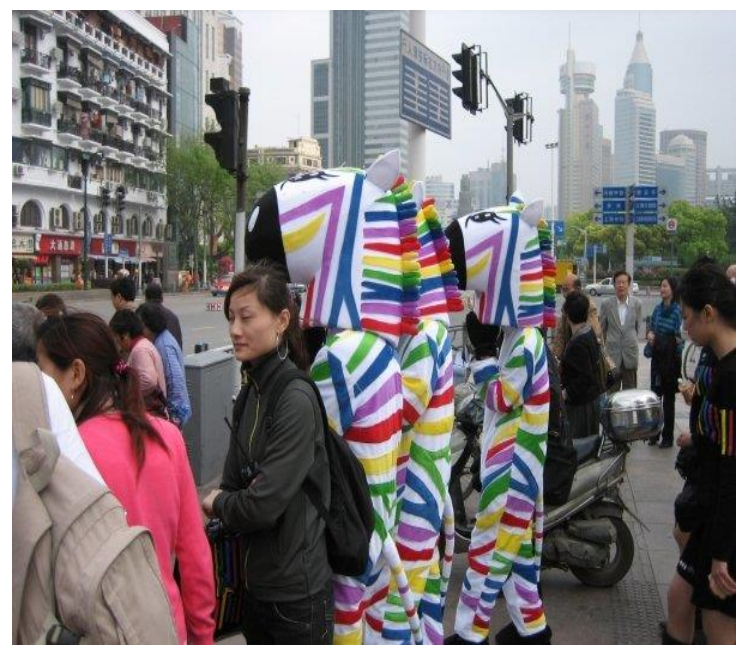

Figure 2a. Zebra picture to represent the colloquial meaning of random

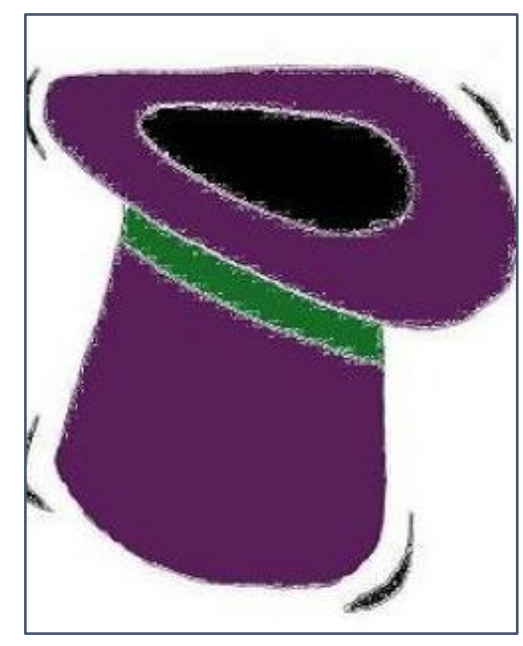

Figure 2b. Hat picture to represent the statistical meaning of random

In the first use of the "Zebra vs. Hat Activity," five times as many students (40\% vs. 8\%) who experienced the Activity defined random in the statistical sense using ideas of probability when compared to the baseline data collected at Step 2 of the cycle (Fig. 1). In addition, the efficacy data (Step 4, Fig. 1) indicate that twice as many students (78\% vs. $34 \%)$ were able to describe correctly the process for taking a random sample compared to previous students of the same instructor who had not experienced the "Zebra vs. Hat Activity" (Kaplan et al. 2014).

In a follow up study, 44\% of 562 students of 6 new instructors who implemented the "Zebra vs. Hat Activity" defined random in the statistical sense using ideas of probability. In comparison, only $25 \%$ of 267 students of instructors at the same institution who did not use the "Zebra vs. Hat Activity" used ideas of probability in their definitions of random. Comparing the students' ability to describe a process of taking a random sample, $40 \%$ of students in the follow-up study who experienced the "Zebra vs. Hat Activity" were able to give complete directions for taking a random sample as compared to $30 \%$ of the students at the same institution who did not experience the "Zebra vs. Hat Activity." Among both groups - those who did and did not experience the "Zebra vs. Hat Activity"-about $28 \%$ of students were able to provide more vague, but not incorrect, descriptions of taking a random sample. 


\section{Developing New Activities}

After the initial success of the "Zebra vs. Hat Activity" in the improvement of student definitions and content knowledge about randomness and random sampling, six faculty members participated in a study aimed at designing other interventions using the cyclic process described above. The instructors attended a one and a half-day summer workshop in which they were introduced to the concept of and research behind lexical ambiguity. The instructors brainstormed about other words used in introductory statistics that might possess lexical ambiguity. As part of the planning process for the workshop, the instructors had indicated potential target words. The authors were able to prepare results from student responses collected previously at other institutions for some of the words chosen initially by the instructors. These results were shared and discussed at the workshop. At the end of the first day of the workshop, each instructor selected two words as the focus of study within his or her classes.

During the fall 2015 semester, each instructor developed at least one activity related to the word(s) chosen after the summer workshop. Twice a month during the fall 2015 semester, the instructors met with the authors of this paper and an undergraduate student who provided support. During these meetings, which typically lasted 45 minutes to an hour, student results for the target words were presented and draft activities were discussed. By the beginning of winter 2016 semester, two different activities were developed for the word pair parameter and statistic. In addition, these activities incorporated the words population and parameter. Two different activities were also developed for the word pair normal and average. One activity was developed for each of the two word pairs of skew and bias and correlation and association. Lastly, one activity was developed for the word residual. The newly developed activities were implemented during the winter 2016 semester by their respective developers and were adopted and adapted by another instructor for use in the fall 2016 semester. All of the activities developed met the desired little time (LT) aspect for such activities, taking between 2 and 8 minutes to implement in class. In this paper we summarize the process and initial findings for the activities developed to target the word-pair parameter and statistic.

Baseline data collected from undergraduate students using the word parameter indicated that the most common colloquial meanings are a rule, characteristic, or condition for inclusion or a limit or boundary. For example, student responses included "a parameter is a rule or guideline to be followed" or "the boundary of something, like a town." Some students clearly confused the two words parameter and perimeter by indicating not just a boundary, but specifically referencing the length of the boundary. Such responses include "parameter is the total outside length of a figure" or "the sum of the length of the 
four sides of a shape." After instruction with no attention to the lexical ambiguity, when students were asked to define parameter as a statistical term half of the students gave a correct statistical definition of parameter, but one-third of students still gave a colloquial definition of the term.

The baseline data also indicated that many students colloquially interpret the word statistic as Statistics, the discipline that is the study of data. In addition, students tended to provide examples of statistics, such as shooting percentage, batting averages, or unemployment rates, or used the term to describe information that is learned from data such as a result or prediction. After instruction with no attention to lexical ambiguity, when students were asked to define statistic as a statistical term, about $60 \%$ of students defined statistic as a piece of information or a calculated value with no mention of a sample or a population, or as a number or set of numbers that were observed but not calculated. Only about $25 \%$ of students gave a correct statistical definition for statistic at the end of the semester.

Two activities were created to target the word pair parameter/statistic: All vs. Small and Candy Jar. The All vs. Small activity was modeled closely on the Zebra vs. Hat Activity although, instead of contrasting the colloquial and technical meanings of the words, All vs. Small exploits the contrast between the population and the sample. The population is the All, and information about the All is the parameter. The sample is the Small, and the information about the Small is the statistic. In the Candy Jar Activity, the definition of parameter in the everyday sense is introduced by the use of a foil-wrapped candy that is too large to be put into the container (Fig. 3a). Because of its size, the foil-wrapped candy does not meet a required characteristic or condition for inclusion in the population. In other words, it does not fulfill the required parameters for inclusion in the population. Figure $3 \mathrm{~b}$ shows two jars with colored-coated chocolate candies; the larger jar represents the population and the smaller one represents the sample with emphasis on the statistical meaning of parameter as a summary measure from the population. Video files of instructors using the All vs. Small and Candy Jar activities can be found at https://hilt-statistics.wikispaces.com/.

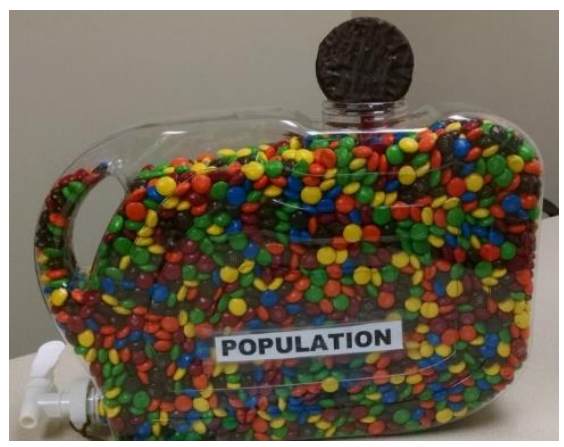

Figure 3a. Parameter (colloquial use of the term, candy population)

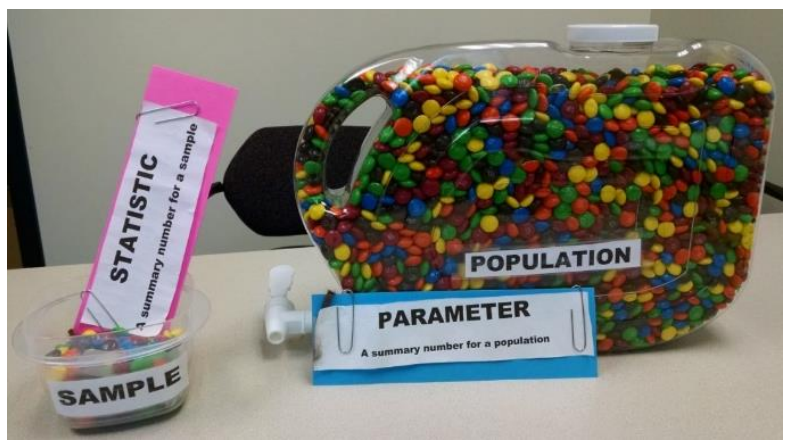

Figure 3b. Parameter (statistical use of the term, candy population) 
Efficacy data indicated after instruction that $57 \%$ of 74 students who experienced one of the two Parameter/Statistic Activities gave a correct statistical definition or example of parameter compared to $37 \%$ of 30 students who experienced neither activity. Perhaps of more importance, only $4 \%$ of the students who experienced one of the activities gave a colloquial definition of parameter compared to $16 \%$ of students who experienced neither activity. In addition, $69 \%$ of students who experienced the activities gave a correct definition or example of statistic compared to $50 \%$ of students who did not experience an activity. Finally, on a question embedded in the course final exam designed to test content knowledge, the ability to recognize a description of a parameter improved: $66 \%$ of students who experienced one of the activities responded correctly compared to $36 \%$ of students who did not experience one of these activities. These results indicate that the Parameter/Statistic Activities meet the desired high impact (HI) aspect for the created activities.

\section{Discussion}

The intent of this paper is to provide Numeracy readers with an overview of lexical ambiguity including the need for attention to the use of such words in courses designed to foster QL and QR competencies. We hope that this information alone will prompt instructors of courses designed to help students develop these competencies to consider carefully their use of language and to identify potentially problematic words. In addition, we present a promising method to address discipline-specific words that are lexically ambiguous.

In particular, addressing the lexical ambiguity of words used in the instruction begins with a recognition that words may have different meanings for students than they do for instructors; without careful attention students may not develop the language of the domain being taught correctly. Once the difficult words have been noted, they should be investigated to determine the nature and impact of the differences between colloquial and technical uses on student learning. The nature of student colloquial notions about the terms and the misunderstandings that exist after typical instruction can be exploited in the creation of short activities designed to help students learn the correct technical definition for the lexically ambiguous terms. The activities designed to target statistical understanding of concepts described by the words random, parameter, and statistic, show an initial positive effect both on students' abilities to define the words and on their capacity to answer content questions around the words. Through both their efficacy at improving student learning and their relatively short length (typically about five minutes) these activities meet the criterion for High Impact, Little Time (HILT). Activities developed for other words had more 
mixed results, indicating that activity development may require several cycles of testing and revision using results from student-level data.

Note we have not claimed or assessed statistical significance of the results presented. The study design did not include random assignment of students to the treatments (instructors or activities), and while every effort was made to find comparable classes to use as a comparison group, no measures were collected to assess the similarity between the treatment and comparison groups. Furthermore, it might be argued that differences in student learning could be due to the extra time the instructors met with peers and discussed teaching or their overall attention to vocabulary as a result of their inclusion in the study protocol.

In order to address these limitations, additional instructor and student-level data have been collected, though not yet analyzed. The instructors in our study implemented at least one activity that they did not create in a subsequent semester. The results associated with these data will be used to assess the efficacy of the activities as used by instructors who were not the original authors and in instances in which there may be a lack of fidelity to the original intent of the activity. In addition, all of the activities created to date, including videorecordings of instructors using the activities in class and the materials needed to incorporate the activities into a class and results from preliminary analyses, are published on a publicly available wikispace (https://hiltstatistics.wikispaces.com/). We are recruiting faculty from other institutions to use the existing activities and/or create new activities with the intent of continuing to use the activity development cycle (Fig. 1) with the new instructors. Faculty interested in using or creating activities designed to target lexically ambiguous words in statistics or other disciplines are invited to contact the authors to be added to our distribution list.

\section{Acknowledgments}

This paper is based upon work supported by the National Science Foundation under Grant No. 1504013. Any opinions, findings, and conclusions or recommendations expressed in this material are those of the authors and do not necessarily reflect the views of the National Science Foundation. The authors would also like to thank the statistics instructors, who worked with us to create and pilot test the activities described, and the students, who helped with data collection and analysis. Finally, we are grateful to the reviewers and editors whose constructive comments guided our writing and helped us craft the current manuscript. 


\section{References}

Adams, Thomasenia L., Fiona Thangata, and Cindy King. 2005. "“Weigh' to Go: Exploring Mathematical Language." Mathematics Teaching in the Middle School 10 (9): 444-48.

Albert, James H. 2003. "College Students' Conceptions of Probability." The American Statistician 57 (1): 37-45. https://doi.org/10.1198/0003130031063

Barwell, Richard. 2005. "Ambiguity in the Mathematics Classroom." Language and Education 19 (2): 118-26. https://doi.org/10.1080/09500780508668667

Brown, Bryan A. 2006. "'It Isn't No Slang That Can Be Said about This Stuff': Language, Identity, and Scientific Discourse." Journal of Research in Science Teaching 43 (1): 96-126. https://doi.org/10.1002/tea.20096

_ First' Approach to Science Teaching." Journal of Research in Science Teaching 45 (5): 529-53. https://doi.org/10.1002/tea.20255

Brown, Bryan A. and Eliza Spang. 2008. "Double Talk: Synthesizing Everyday and Science Language in the Classroom." Science Education 92 (4): 708-32. https://doi.org/10.1002/sce.20251

Durkin, Kevin and Beatrice Shire. 1991a. "Lexical Ambiguity in Mathematical Contexts." In Language in Mathematical Education: Research and Practice, Kevin Durkin and Beatrice Shire (eds.), 71-84. Philadelphia, PA: Open University Press.

_ 1991b. "Primary School Children's Interpretations of Lexical Ambiguity in Mathematical Descriptions." Journal in Research in Reading 14 (1): 46-55. https://doi.org/10.1111/j.1467-9817.1991.tb00005.x

Espinet, Mariona, Mercè Izquierdo, Josep Bonil, and S. Lizette Ramos De Robles. 2012. "The Role of Language in Modeling the Natural World: Perspectives in Science Education.” In Second International Handbook of Science Education, Barry J. Fraser, Kenneth Tobin, and Campbell J. McRobbie (eds.), 1385-1403. Dordrecht, The Netherlands: Springer. https://doi.org/10.1007/978-1-4020-9041-7_89

GAISE. 2006. College Report of the Guidelines for Assessment and Instruction in Statistics Education Project. http://www.amstat.org/education/gaise/GAISECollege.htm

Gal, Iddo. 2003. "Expanding the Conceptions of Statistical Literacy: An Analysis of Products from Statistics Agencies." Statistics Education Research Journal 2 (1): 3-21.

Garvin-Doxas, Kathy and Michael W. Klymkowsky. 2008. "Understanding Randomness and Its Impact on Student Learning: Lessons Learned from Building the Biology Concept Inventory (BCI)." CBE Life Sciences Education 7 (2): 227-33. https://doi.org/10.1187/cbe.07-08-0063 
Kaplan, Jennifer J., Diane G. Fisher, and Neal T. Rogness. 2009. "Lexical "Ambiguity in Statistics: What Do Students Know About the Words: Association, Average, Confidence, Random and Spread?" Journal of Statistics Education 17 (3). http://www.amstat.org/publications/jse/v17n3/kaplan.html

Kaplan, Jennifer J., Diane G. Fisher, and Neal T. Rogness. 2010. "Lexical Ambiguity in Statistics: How Students Use and Define the Words: Association, Average, Confidence, Random and Spread." Journal of Statistics Education 18 (2). http://www.amstat.org/publications/jse/v18n2/kaplan.pdf

Kaplan, Jennifer J., Neal T. Rogness, and Diane G. Fisher. 2014. "Exploiting Lexical Ambiguity to Help Students Understand the Meaning of Random." Statistics Education Research Journal, 13 (1): 9-24.

Karaali, Gizem, Edwin H. Villafane Hernandez, and Jeremy A. Taylor. 2016. "What's in a Name? A Critical Review of Definitions of Quantitative Literacy, Numeracy, and Quantitative Reasoning." Numeracy. 9 (1): Article 2. https://doi.org/10.5038/1936-4660.9.1.2

Lavy, Ilana and Michal Mashiach-Eizenberg. 2009. "The Interplay Between Spoken Language and Informal Definitions of Statistical Concepts.” Journal of Statistics Education 17 (1). http://www.amstat.org/publications/jse/v17n1/lavy.html

Lemke, Jay L. 1990. Talking Science: Language, Learning and Values. Norwood, NJ: Ablex Publishing Corporation.

Lesser, Lawrence M. and Matthew S. Winsor. 2009. "English Language Learners in Introductory Statistics: Lessons Learned from an Exploratory Case Study of Two Pre-Service Teachers." Statistics Education Research Journal, 8 (2): 5-32. http://iase-web.org/documents/SERJ/SERJ8(2)_Lesser_Winsor.pdf

Lesser, Lawrence M., Amy E. Wagler, Alberto Esquinca, and M. Guadalupe Valenzuela. 2013. "Survey of Native English Speakers and Spanish-Speaking English Language Learners in Tertiary Introductory Statistics." Statistics Education Research Journal 12 (2): 6-31. http://iaseweb.org/documents/SERJ/SERJ12(2)_Lesser.pdf

Leung, Constant. 2005. "Mathematical Vocabulary: Fixers of Knowledge or Points of Exploration.” Language and Education, 19 (2): 127-35. https://doi.org/10.1080/09500780508668668

Makar, Katie and Jere Confrey. 2005. "'Variation-Talk': Articulating Meaning in Statistics." Statistics Education Research Journal 4 (1): 27-54. http://iaseweb.org/documents/SERJ/SERJ4(1)_Makar.pdf

Neibert, Kai, Sabine Marsch, and David F. Treagust. 2012. "Understanding Needs Embodiment: A Theory-Guided Reanalysis of the Role of Metaphors and 
Analogies in Understanding Science." Science Education 96 (5): 849-77. https://doi.org/10.1002/sce.21026

Pinker, Steven. 1994. The Language Instinct: How the Mind Creates Language. New York, NY: HarperCollins Publisher. https://doi.org/10.1037/e412952005-009

Rangecroft, Margaret. 2002. "The Language of Statistics." Teaching Statistics 24 (2): 34-37. https://doi.org/10.1111/1467-9639.00080

Rector, Meghan A., Ross H. Nehm, and Dennis Pearl. 2013. "Learning the Language of Evolution: Lexical Ambiguity and Word Meaning in Student Explanations." Research in Science Education 43 (3): 1107-133. https://doi.org/10.1007/s11165-012-9296-z

Roth, Wolff-Michael 2005. Talking Science: Language and Learning in Science Classrooms. Lanham, MD: Rowman \& Littlefield Publishers, Inc.

Shultz, Thomas R. and Robert Pilon. 1973. "Development of the Ability to Detect Linguistic Ambiguity." Child Development 44 (4): 728-33. https://doi.org/10.2307/1127716

Thompson, Denisse R. and Rheta N. Rubenstein. 2000. "Learning Mathematics Vocabulary: Potential Pitfalls and Instructional Strategies.” Mathematics Teacher 93 (7): 568-74.

Tomlinson, Jane, Paul J. Dyson, and John Garratt. 2001. "Student Misconceptions of the Language of Error." University Chemistry Education 5: 1-8.

Tunstall, Samuel L. 2016. "Words Matter: Discourse and Numeracy." Numeracy 9 (2): Article 5. http://dx.doi.org/10.5038/19364660.9.2.5

Vacher, H. L. 2014. "Looking at the Multiple Meanings of Numeracy, Quantitative Literacy, and Quantitative Reasoning." Numeracy 7 (2): Article 1. http://dx.doi.org/10.5038/1936-4660.7.2.1 